\title{
A INFORMAÇÃO ENTRE SENTIDO E VALIDADE: GLOSAS RECONSTRUTIVAS
}

\author{
Vinícios Souza de Menezes \\ Filiação Institucional: Doutorando \\ IBICT/UFRJ \\ Email: menezes.vinicios@gmail.com
}

\begin{abstract}
Resumo
Trata-se de um encontro dialogal da virada pragmático-linguística filosofia com a informação e a teoria crítica da sociedade. $\mathrm{O}$ escopo de tal encontro é a busca pelas possibilidades férteis que a teoria crítica da sociedade pósvirada linguística oferece para os estudos sociais da informação, em especial, o método da reconstrução racional, cujo propósito reconstrutivo traz consigo dois conceitos fundamentais que se assemelham e coexistem com as ações prático-cognitivas da informação: sentido e validade. Versa acerca de um encontro público entre as pretensões racionais do uso público da linguagem e seu eco pelas veredas plurais dos estudos informacionais. Ao final das glosas, ficam vestígios e indícios de uma tarefa humanitária e emancipatória porvir, em seu detalhe informacional.
\end{abstract}

Palavras-chave: Informação. Reconstrução. Teoria Crítica. Sentido. Validade.

\section{INFORMATION BETWEEN MEANING AND VALIDITY: GLOSSES RECONSTRUCTIVE}

\begin{abstract}
It is a dialogical meeting of the pragmatic-linguistic turn philosophy with information and critical theory of society. The scope of this meeting is the search for fertile possibilities that the critical theory of society linguistic post-oriented provides for the social studies of information, in particular the method of rational reconstruction, the purpose of reconstructive brings with it two key concepts that are similar and coexist with the practicalcognitive actions of information: meaning and validity. Versa about a public meeting between the rational claims of the public use of language and its echo the plural paths of informational studies. At the end of glosses, are traces and evidence of a humanitarian task and future emancipatory in its informational detail.
\end{abstract}

Keywords: Information. Reconstruction. Critical Theory. Meaning. Validity

\section{Situação hermenêutica de partida}

O conceito de informação na modernidade ganha em polissemia e perde em clareza. Afortuna-se, por ora, pela conectividade das fontes, das abordagens, perspectivas e resgates anamnésicos que enriquecem a sua semântica e a sua pragmática - "pan-information" (BRIER, 2014, p. 28) -, outrora, apresenta-se com um forte déficit de clareza, podendo ser (c) (1)(2) 
imperativamente quase qualquer coisa - "informação é tudo! ”, lema de inúmeras rádios, jornais, magazines e sítios de notícias. Tal celeuma nos deixa atordoados e, de certo modo, atados perante o desconhecimento prático (uso) acerca do que estamos ao fim e ao cabo falando. Trata-se de uma busca pelas gramáticas da informação. Não menos polissêmicas, contudo, mais precisas em seus jogos informativos contextualizados em seus respectivos tópos de uso (logeion). Não se trata de contextualismo relativista. Trata-se de regras estruturadas linguisticamente cujo fundo prático-cognitivo é decidido intersubjetivamente entre os pares que compõem a comunidade discursiva. Também não se trata de com isto alcançarmos ou nos encontrarmos com o extramundano "claro e evidente" cartesiano; ao contrário, a clareza e a evidência acerca do que de fato seja a informação em seus contextos de uso são uma conquista construtivamente social e partilhada entre os concernidos. Em sociedades mundividencialmente plurais, tais conquistas são sempre muito mais complexas diante do emaranhado de relações e interesses envolvidos, cujo fim nem sempre é intercompreensivo. Destarte, toca-se na questão do sentido e da validade de um conceito.

As demandas teleológicas das sociedades modernas estão sobrecarregadas pelos impulsos sistêmicos dos meios de controle: dinheiro e poder. A informação não está alheia a tais demandas. O inverso. O projeto neoliberal de sociedade nascido nos idos de 1960 nomeou tal sociedade vindoura e eldorada de "sociedade da informação"1. Jogando com a pretensão moderna do esclarecimento (aufklärung) que carregaria o ideal de tal sociedade, os avanços sistêmicos corromperam, em boa parte, tais aspirações e num jogo de ocultamento e prejuízo de significação, transformaram a informação, outrora um recurso de objetivação de sentido destinado ao aprendizado e a instrução, em um mero meio para aquisição de um fim.

A situação problemática delineia-se a partir da concepção da sociedade da informação como um programa neoliberal de universalização das dinâmicas econômicas dos mercados, onde a herança da modernidade é lida, por muitos ${ }^{2}$, em geral neoconservadores, unidimensionalmente como um aumento incremental inovativo de complexidade dos processos capitalistas de desenvolvimento social, ou seja, o projeto da modernidade inacabada renovado pela perspectiva e expectativas contemporâneas de realização da sociedade da informação é reduzido assimetricamente ao paradigma da produção ${ }^{3}$, sendo as estruturas

\footnotetext{
1 "La ideología de la sociedad de la información no es otra que la del mercado. Está en sinergia con los supuestos de reconstrucción neoliberal del mundo." (MATTELART, 2002, p. 168)

${ }^{2}$ Conferir o texto de Jürgen Habermas (1992): A modernidade: um projeto inacabado?

3 “[...] o paradigma da produção, amputado das suas raízes na filosofia da reflexão, traz consigo, caso se destine a prestar idênticos serviços no campo da teoria da sociedade, pelo menos, três novos problemas: 1) o paradigma da produção restringe o conceito de práxis tanto que se põe a questão de saber como se comporta o tipo de atividade paradigmática do trabalho, ou da fabricação de produtos, em relação ao conjunto de todas as restantes
} 
normativas emancipatórias do paradigma intercompreensivo ${ }^{4}$ inscrito na modernidade compreensibilidade/inteligibilidade, reflexividade crítica, universalismo interativo ("para todos") e individuação por socialização -, restringidas aos meios generalizáveis do dinheiro, do poder administrativo e da técnica (pela técnica). O princípio de organização da sociedade capitalista centrado na razão de um macrossujeito (information man $^{5}$ ) sufoca as energias utópicas por meio da sobredeterminação da economia e da transformação da política em um epifenômeno das relações econômicas. O enfraquecimento das energias utópicas da sociedade da informação estaria associado à vinculação deste programa social ao paradigma economicista da produção, por meio da linha reformista tecnocrática e do modelo democrático mercadológico ${ }^{6}$ promovido por esta formação social dominante.

Inúmeros diagnósticos contemporâneos apontam facetas inovativas ao mesmo tempo em que apresentam patologias que recobrem as atuais configurações societais, tão multidiversas e ricas em possibilidades para uma vida melhor em conjunto, quanto simultaneamente arrefecido pelo cerceamento das vozes informativas e comunicativas, promovido pelo uso privado da razão estratégico-instrumental e insinuado pelos interesses particulares, alheios ao bem comum. Nesta linha existem as teses bourdieusianas (BOURDIEU, 1983) que argumentam acerca da naturalização simbólico-material da economia nas relações sociais (estruturalismo genético), as proposições de Richard Sennett a respeito do "novo capitalismo social" (2006) e do efeito do uso privado da razão para o declínio do homem público (1988), as descrições de Manuel Castells (1999; 2000; 2001) de uma sociedade em rede como sociedade informacional, cujos desdobramentos reais após os prognósticos futuristas dos anos 1970 demarcam um aumento das desigualdades e das fragilidades humanas em face de um projeto distópico de sociedade; Alistair Duff (2008) dirá

formas de manifestação cultural de sujeitos com capacidade de se exprimirem verbalmente e de agirem. [...] 2) $\mathrm{O}$ paradigma da produção determina o conceito da práxis num sentido de tal modo naturalista que se levanta a questão de saber se poderão obter-se conteúdos normativos a partir do processo osmótico entre a sociedade e a natureza. [...] 3) O paradigma da produção confere um significado tão nitidamente empírico ao conceito de práxis, que se levanta a questão de saber se este paradigma não perderá a sua plausibilidade com o fim, historicamente previsível, da sociedade do trabalho." (HABERMAS, 1998, p. 84)

4 Afinal, o paradigma da intercompreensão busca o entendimento mútuo, a eticidade do reconhecimento intersubjetivo, que passa pela potência fertilizadora da cultura, da sociedade e da personalidade.

"O trabalho da desconstrução, por mais entusiasta que seja, só pode ter consequências definíveis quando o paradigma da consciência de si, da auto-referência de um sujeito que conhece e age isoladamente é substituído por outro, pelo paradigma da intercompreensão, isto é, da relação intersubjetiva de indivíduos, que socializados através da comunicação, se reconhecem mutuamente. Só então surge a crítica do pensamento ordenador da razão centrada no sujeito de forma determinada - nomeadamente como crítica ao "logocentrismo" ocidental a qual diagnostica não um excesso mas um défice de razão.” (HABERMAS, 1998, p. 288)

${ }^{5} \mathrm{O}$ "information man" concebe a "information as an economic good" (BATES, 1990, p. 379), não por menos, "the notion of information man" é análoga à do "economic man". (ROBERTS, 1982, p. 93)

${ }^{6}$ Cf. Habermas (2014) "No turbilhão da tecnocracia: um apelo por solidariedade europeia." 
que o que há é uma "crise normativa da sociedade da informação" - como exemplos, apresenta: o esfacelamento dos direitos autorais, a perda da privacidade em face da vigilância global do ciberespaço e a exclusão digital, categoria que ganha grandes proporções perante a conversão do mundo físico em digital -, isto é, a sociedade da informação já não pode ser vista apenas como uma sociedade técnico-científica, outros conjuntos de problemas apresentam-se e chamam atenção para a dimensão ético-política - normativa -, suprimida nas linhas iniciais de concepção e atualmente foco da "crise normativa multidimensional" da sociedade da informação. Duff argumenta que a sociedade da informação necessita "recarregar seus ideais utópicos"” e para tal aponta, por meio da teoria da justiça distributiva de John Rawls, um caminho para uma "utopia viável da informação", fundada na "comunhão igualitária" entre os homens.

Alistair Duff argumenta contra as propostas da teoria crítica e do neoliberalismo para a reforma da sociedade da informação, diante do déficit de normatividade, segundo o autor, destas duas linhas de pensamento. Este texto concorda com Axel Honneth (2009) em Patologías de la razón: historia y actualidad de la teoría crítica, quando diz que a teoria crítica conforme a fisionomia traçada pela primeira geração de Frankfurt possuía um déficit de normatividade, onde as estruturas normativas foram postas em segundo plano em detrimento do relevo da dimensão cognitivo-instrumental para as análises desta geração; contudo, a segunda e terceira geração da teoria crítica partilha de um projeto reconstrutivo da sociedade, cujo foco corretivo passa pelas estruturas normativas da sociedade - o programa habermasiano definido como reconstrutivo racional (segunda geração) e o programa honnethiano concebido como reconstrutivo normativo (terceira geração). Dito isso, os traços para um programa alternativo da sociedade da informação, ou ao menos, para a informação enquanto conceito, estariam atravessados por uma perspectiva reconstrutiva que considera de modo compreensivo os potenciais libertadores das "teorias tradicionais" e das "teorias críticas" (HORKHEIMER, 1975, p. 125-162), perante o propósito reconstrutivo-libertador das energias políticas paralisadas.

No seio das sociedades plurais contemporâneas, onde se encontra a perspectiva da sociedade da informação, as ramificações alternativas emergem, dentre tantas efervescentes vielas, no curso das ações sociais, especialmente as solidárias cujos deslocamentos almejam

\footnotetext{
${ }^{7}$ Luc Boltanski e Ève Chiapello (2009, p. 28, grifo nosso) argumentam que os dispositivos críticos atuais não oferecem nenhuma alternativa de envergadura para fazer oposição ao "novo espírito do capitalismo": "Só restam a indignação em estado bruto, o trabalho humanitário, o sofrimento como espetáculo e, sobretudo desde as greves de dezembro de 1995, ações centradas em causas específicas (moradia, estrangeiros em situação irregular etc.) que, para adquirirem a amplitude de representações mais adequadas, carecem de modelos de análise renovados e de utopia social."
} 
relações mais distributivas interpares ${ }^{8}$. Em um mundo onde as ações emaranham-se nas relações eticamente neutralizadas pelas dinâmicas materiais parciais, imperativamente sobrepujadas à condição de totalidade, uma contribuição alternativa ao vigente encontra-se atravessada por um regime acional eticamente orientado - "eticidad democrática" (HONNETH, 2014, 91-96). Cabem às sociedades centralizadas pelos eixos nodais da informação, eminente nas sociedades contemporâneas, instruir ética e politicamente suas ações informacionais ${ }^{9}$, esquivando-se das dissimulações e obscuridades geradas pelo modelo de "sociedade da informação" efetivado nas "obras" informacionais, nutridas pelo apelo ao valor de troca de bens econômicos intangíveis. Perante tal cenário, este texto debruça-se sobre a dimensão humana da ação, em específico, diante das cercanias temáticas, das ações informacionais, tão caras aos postulados humanos de convivência em sociedade ${ }^{10}$, atualmente estremecidos pelo mal-estar que ocupa as mais diversas esferas de valor e afasta o homem de suas dinâmicas éticas de reconhecimento.

Inicialmente, caso se aceite que a argumentação deste texto é de tipo filosófico epistêmico, pode-se postular a afirmação de que a informação é aqui tratada através do horizonte de disponibilidade argumentativa da filosofia social. Considerando a ancoragem da informação no meta-plano hermenêutico social do mundo da vida, a primeira decisão metateórica de Habermas (2010a, p. 29-31) acerca da fundamentação linguística do social é também aqui aceita: sentido e validade são conceitos fundamentais para qualquer projeto reconstrutivo. Não se esquivando desta decisão metateórica, ao invés, indo fortemente ao encontro dela pelas vias hermenêuticas de Capurro (2014a) e seus comentários acerca da figura conceitual da informação em Averróis, onde afirma que a informação na exegese metafísica medieval assemelhava-se em seus jogos de linguagem à noção de "conception" e de "assentiment" - numa linguagem pós-metafísica poderíamos dizer: sentido e validade, ou seja, dentro de uma perspectiva crítico-filológica, a noção de informação se mostra de modo familiar às questões de sentido e validade do projeto reconstrutivo.

A questão da informação reconsiderada através da teoria do significado ampliada à pragmática ultrapassa os limites das tradicionais práticas info-documentárias direcionadas a

\footnotetext{
8 "Lutamos com a linguagem. Estamos envolvidos numa luta com a linguagem" (WITTGENSTEIN, 2000, p. 27)

${ }^{9}$ Os tratados seminais que tratavam da "categoria" da ação abordavam-na de modo imiscuído à "categoria" da ética, onde, agir significaria agir eticamente, com vistas ao "bem".

10 "Desde esta perspectiva, el estudio de las sociedades de la información y del conocimiento es de naturaleza eminentemente ética. Los valores y principios que están en juego en toda sociedad humana y la reflexión ética cotidiana sobre los mismos no se encuentran en un lugar intrasíquico separado del así llamado mundo exterior y del diálogo con los otros, sino que se expresan en un juego de libertades y opciones que va generando cambios en las costumbres individuales y sociales vigentes, el ethos (literalmente: carácter) griego y las mores (costumbres) romanas, basadas en un mundo compartido." (CAPURRO, 2014, p. 8-9)
} 
construção de fatos. Revitalizando essas práticas de construção social de evidências, a pergunta acerca da informação se encaminharia às considerações de relações sociais organizadas normativamente e às competências pragmáticas adquiridas pelos atores nos processos de socialização - intersubjetiva e interobjetiva. Deste modo, a validade adentra o cenário das práticas info-documentárias não somente pela via da pretensão de verdade - “ $A$ document is a proof in support of a fact." (BRIET, 2006, p. 9) - todavia também pela pretensão de correção das relações interpessoais das ações de informação e pela sinceridade das intenções do informante ao tornar pública suas vivências e testemunhos informacionais.

\section{A informação e o programa reconstrutivo da sociedade: entre sentido e validade}

As ciências reconstrutivas se caracterizam pela dimensão social de suas abordagens, em boa parte, pela adoção justificada da compreensibilidade dos seus atos ${ }^{11}$. As ciências reconstrutivas têm como base fundamentadora e justificadora dos seus discursos, o sentido e o reconhecimento dos significados produzidos pelas plurais formas de vida que configuram as comunidades linguísticas. A hermenêutica, em especial, a "virada interpretativa"12 ocorrida após os eventos da segunda grande guerra mundial, fertilizou as abordagens interpretativas do social, deslocando, com o movimento pós-empirista, as perspectivas por ora nomológicas das ciências. Quando se fala de fato ou evidências do mundo após tal guinada, não estamos mais diante de algo mais ou menos unificado, dado naturalmente com precisão e exatidão, transparente ("claro e evidente") e sem controvérsias. O fato verteu-se e o sujeito descentrouse.

$\mathrm{O}$ que a modernidade, em particular, o pensamento realista e naturalista da modernidade cultural, chamou de realidade, não mais corresponde de modo direto com o mundo. Há nesse ínterim de passagem um sentido produzido intersubjetivamente e

\footnotetext{
${ }^{11}$ A respeito de possíveis áreas do conhecimento que estariam na cercania das ciências reconstrutivas, à qual torna-se possível relacionar a Ciência da Informação, diz Habermas (2010a, p. 305): "Esta é a área [das ciências reconstrutivas] de disciplinas como a lógica e a meta-matemática, da linguagem, a ética e a teoria da ação, a estética, a teoria da argumentação, etc. Todas estas disciplinas têm em comum o objetivo de darem conta do saber pré-teórico e do domínio intuitivo de sistema de regras que estão na base da produção e avaliação de enunciados e realizações simbólicos."

${ }^{12}$ Um dos exemplos centrais para a compreensão da entrada e a consequente abertura conferida pelo sentido nas abordagens hermenêuticas é esta perspectiva de Heidegger, ainda que lhe falte o senso prático do reconhecimento intersubjetivo do sentido. Diz-nos Heidegger (2010, p. 58): "O alemão sinnan, sinnen, pensar o sentido, diz encaminhar na direção que uma causa já tomou por si mesma. [...] significa mais do que simples consciência de alguma coisa. Ainda não pensamos o sentido quando estamos apenas na consciência. Pensar o sentido é muito mais. É a serenidade em face do que é digno de ser questionado. [...] No pensamento do sentido, encaminhamo-nos para um lugar onde se abre, então, o espaço que atravessa e percorre tudo que fazemos ou deixamos de fazer."
} 
interobjetivamente - caso aceitemos a potência transformadora dos objetos ${ }^{13}$. Peter Berger e Thomas Luckmann, na obra conjunta "A construção social da realidade: tratado de sociologia do conhecimento", com o propósito de reunir na seara da sociologia do conhecimento as reformulações e os novos problemas do conhecimento e do real, afirmam que "a realidade é construída socialmente" e trata-se da tarefa da sociologia do conhecimento "analisar o processo em que este fato ocorre. $" 14$ (2009, p. 11, grifo nosso) A pergunta de fundo de Berger e Luckmann seria: como um "corpo de conhecimento" chega a ser socialmente estabelecido como "realidade"? Ou seja, em outras palavras, como uma estrutura significativa é reconhecida como válida, ou, de modo mais generalizante, como sentido e validade estruturam linguisticamente o mundo (nas palavras de Wittgenstein, o "tapete da vida"). Esta leitura distancia-se um pouco da perspectiva de Berger e Luckmann, pois no nosso entendimento seriam as regras dos jogos de linguagem e suas gramáticas polimórficas que estabeleceriam os limites interpretativos e a força do sentido estaria implicada na dimensão normativa da linguagem - o que não é o caso de Berger e Luckmann que põem em primeiro plano a esfera subjetiva para suas decisões e justificações argumentativas.

A questão da informação, conforme se pretende tratar aqui através da perspectiva reconstrutiva, relacionar-se-ia diretamente com a ambiência da linguagem e do significado/validade - em associação ao esforço reconstrutivo dos estudos políticoepistêmicos de Maria Nélida González de Gomez, todavia, de modo próprio. Inicialmente, concordes com alguns postulados da literatura da Ciência da Informação acerca do estatuto social e linguístico deste campo, pode-se argumentar que há um eixo vinculativo com as ciências reconstrutivas a partir de: i) a informação pode ser entendida como um conceito fundado nos usos cognitivos, comunicativos e expressivos da linguagem e em suas redes semântico-pragmáticas; ii) são conceitos fundamentais para a Ciência da Informação, o sentido e a validade; iii) perante um plano intersubjetivo comum de regras e normas linguisticamente estruturadas, a informação perfaz-se enquanto uma ação, isto é, o ato de informar outrem sobre algo no mundo; iv) as ações implicadas no ato de informar pressupõem um ator socializado - o informante; este, por sua vez, configura-se por meio das práticas discursivo-informacionais dos contextos de uso.

\footnotetext{
${ }^{13}$ Vários exemplos podem ser dados, contudo, opta-se pela indicação seletiva e representativa para a área, o texto La libertad en la era digital de Rafael Capurro (2014) e o capítulo quarto, Será que livros fazem revoluções?, do livro Origens culturais da revolução francesa de Roger Chartier (2009). Esses dois exemplos habitam a instância híbrida da contemporaneidade, entre o mundo físico e o digital.

${ }^{14}$ Nos termos de Berger e Luckmann (2009, p. 11) a realidade é "uma qualidade pertencente a fenômenos que reconhecemos terem um ser independente de nossa própria volição (não podemos 'desejar que não existam')" e o conhecimento é "a certeza de que os fenômenos são reais e possuem características específicas".
} 
O método reconstrutivo age de modo a pôr em perspectiva as teorias que se mostram potencialmente emancipadoras, mas que, todavia, encontram obstáculos - "patologias das sociedades" - para a sua realização. Não se trata de uma restauração de uma imagem de mundo de outrora, nem de um renascimento de algo adormecido ou por ora esquecido, ou seja, a reconstrução não é uma anamnese com uma mirada na restituição de algo que foi esquecido, escapou ou foi sacralizado; trata-se de reconsiderar o potencial emancipatório teórico-prático de uma teoria e seus plexos acionais irrealizados perante as possibilidades contemporâneas de realização. Todavia, "toda reconstrução racional tem um estatuto hipotético.” (HABERMAS, 2010a, p. 305)

Se trata de diversas acometidas para elaborar um enfoque teórico que yo entiendo como reconstrucción [...]. Restauración significaria el retorno a un estado inicial entre tanto corrompido: pero mi interes por Marx y Engels ni es dogmático ni tampoco histórico-filosófico. Renacimiento querría decir la renovación de uma tradición entre tanto sepultada: pero el marxismo no tiene ninguna necesidad de semejante cosa. Reconstrucción significa, em nuestro contexto, que se procede a desmontar uma teoria y luego a recomponerla em forma nueva con el único objeto de alcanzar mejor la meta que Ella misma se há impuesto: tal es el modo normal de habérselas com uma teoria que en algunos puntos necesita una revisión, pero cuya capacidad estimulante dista mucho de estar agotada. (HABERMAS, 1992, p. 9, grifo nosso)

Com o propósito de pôr em evidência algumas teorias desta "moderna invenção" chamada informação (DAY, 2001), que inspiraram o que veio a ser designado como sociedade(s) da informação, sendo esta, na perspectiva de González de Gómez (2011, p. 225), a representante que "ocupa o lugar e assume as expectativas que outrora eram projetadas na Modernidade", busca-se pôr algumas glosas reconstrutivas e críticas com o propósito do reconhecimento da informação como elemento relacionado ao sentido e a validade, e, por sua vez, um ativo emancipatório das sociedades modernas.

\subsection{Informação, sentido e validade}

Manfredo de Oliveira (1996, p. 204-205) sob o pano de fundo da discussão do enquadramento informacional heideggeriano e do sufocamento da vida humana perante o bloqueio da abertura da linguagem causado pela informação (técnica), fala de uma humanidade inautêntica onde a "linguagem como informação" pressuporia uma relação instrumental com o mundo fundada nos paradigmas das "teorias da consciência e da representação" - informação como "conteúdo cognitivo e sentido" em Frege (empirismo) e 
como "lógica [psicológica] da informação" (mentalismo) em Wittgenstein. A informação na "ontologia hermenêutica" heideggeriana seria "puro instrumento" da técnica, sua realização mais acabada, representada pela "nova ciência básica que se chama cibernética" (HEIDEGGER, 1973, p. 270), diz-nos Heidegger em seu texto "O fim da filosofia"; e complementa: "as ciências interpretarão tudo [...] sob o ponto de vista da técnica" (1973, p. 271), isto é, sob o ponto de vista totalizador da informação (cibernética), a filosofia teria se deparado com o seu estágio terminal e a "humanidade se realiza na práxis social" da cientificidade (1973, p. 270).

Esta ciência [cibernética] corresponde à determinação do homem como ser ligado à práxis na sociedade. Pois ela é a teoria que permite o controle de todo planejamento possível e de toda organização do humano. A cibernética transforma a linguagem num meio de troca de mensagens. As artes tornam-se instrumentos controlados e controladores da informação. (HEIDEGGER, 1973, p. 270, grifo nosso)

Antes de qualquer análise deste forte antagonismo descrito por Heidegger, trata-se de mostrar a referência sobre a qual o filósofo alemão tece suas críticas, em particular, à cibernética de Norbert Wiener. O escopo da cibernética, manifesta Wiener (1968, p. 17) em "Cibernética e sociedade: o uso humano de seres humanos", é "desenvolver uma linguagem e técnicas que nos capacitem, de fato, a haver-nos com o problema do controle e da comunicação em geral", e continua atribuindo centralidade à informação, "as ordens de comando por via das quais exercemos controle sobre nosso meio ambiente são uma espécie de informação" (1968, p. 17, grifo nosso). A informação na teoria do "governo" cibernético (kubernetes, do grego governador) de Wiener não possui o estatuto puramente entrópico e sem significado como em Shannon e Weaver ${ }^{15}$ - ainda que diga que "qualquer espécie de informação" esteja sujeita à entropia, contudo, "em comunicação e controle, estamos sempre em luta contra a tendência da Natureza de degradar o orgânico e destruir o significativo. "16 (WIENER, 1968, p. 17) O modelo "maquínico" fraco de significação de Wiener é o das ciências naturais e a ideia de fundo é aquela contida, em geral, na teoria dos

\footnotetext{
15 "Os conceitos de informação desenvolvidos nesta teoria, parecem ser bizarros e frustrativos - frustrativos porque em nada se relacionam com o conceito de significado, e bizarro porque não transaciona com uma mensagem singularizada, muito ao contrário trata do caráter estatístico do efeito total das mensagens; bizarro outra vez, devido a nestes termos estatísticos as duas palavras informação e incerteza, encontrarem-se estreitamente associadas, de fato consorciadas." (SHANNON; WEAVER, 1975, p. 28)

${ }^{16}$ A respeito do grau de significação atribuído por Wiener à informação, diz o próprio: "O semântico [...] se relaciona com o significado e se torna manifesto, por exemplo, nas dificuldades de traduzir de uma para outra língua em que a correspondência imperfeita entre os significados das palavras restringe o fluxo de informação de uma para outra." (WIENER, 1968, p. 78, grifo nosso) Deste modo, para que a circulação da informação aconteça e torne-se verificável, é imprescindível considerar uma "semântica da informação".
} 
sistemas (com suas variações de abordagens), em que a informação no meio ambiente está carregada de complexidade e cabe ao sistema num processo de troca de mensagens estabilizála, reduzi-la para os usos instrumentais/estratégicos dos sistemas. Face ao meio ambiente entrópico, a informação seria como descrita pela teoria matemática da comunicação: "análoga ao volume de liberdade de escolha que temos para construir as mensagens" (SHANNON; WEAVER, 1975, p. 13), porém, com um mínimo de conteúdo significativo ${ }^{17}$.

A crítica heideggeriana à cibernética como ciência básica que tem como elemento central da técnica a informação vem insuflada de uma crítica à modernidade como movimento histórico-filosófico orientado pela compreensão enrijecida da metafísica onto-teo-lógica, onde a cibernética representaria a imagem finalística hegeliana de uma realização científica prédeterminada pelo curso da história. Controle, planejamento, administração, governo são figuras prático-conceituais que associadas ao projeto da modernidade, conforme lido por Heidegger, levaram à "destruição do pensamento do sentido". A saída de Heidegger para tal situação patológica seria a "passagem para o poético" (NUNES, 2012); estaria no plano da expressividade subjetiva do ser a saída, ou, nos termos de Heidegger, "a salvação" da humanidade. De fato, Heidegger chamou a atenção para um plano por ora olvidado pelos diagnósticos de época; contudo, neste "espaço que atravessa e percorre tudo que fazemos ou deixamos de fazer", ao qual Heidegger nomeia como o lugar do "pensamento do sentido", seria de difícil estabelecimento sem o reconhecimento intersubjetivo e a validade das regras acionais - dimensão pouco desenvolvida por Heidegger. Logo, a associação da informação com a técnica, com o controle, com a administração, o planejamento, a liberdade de escolha, o comando, enfim, com a práxis social da humanidade seria um espaço teórico-prático fértil para um projeto reconstrutivo.

Perante os "padrões de racionalidade pretensamente universais" pressupostos pelo agir comunicativo que alicerçam o projeto reconstrutivo da sociedade, as teorias de fundo

17 “O homem está imerso num mundo ao qual percebe pelos órgãos dos sentidos. A informação que recebe é coordenada por meio de seu cérebro e sistema nervoso até, após o devido processo de armazenagem, colação e seleção, emergir através dos órgãos motores, geralmente os músculos. [...] a informação recebida pelos órgãos sinestésicos se combina com o cabedal de informação já acumulada para influenciar as futuras ações. Informação é o termo que designa o conteúdo daquilo que permutamos com o mundo exterior ao ajustar-nos a ele, e que faz com que nosso ajustamento seja nele percebido. $\mathbf{O}$ processo de receber e utilizar informação é o processo de nosso ajuste às contingências do meio ambiente e de nosso efetivo viver nesse meio ambiente. As necessidades e a complexidade da vida moderna fazem, a este processo de informação, exigências maiores do que nunca, e nossa imprensa, nossos museus, nossos laboratórios científicos, nossas universidades, nossas bibliotecas e nossos compêndios estão obrigados a atender às necessidades de tal processo, sob pena de malograr em seus escopos. Destarte, comunicação e controle fazem parte da essência da vida interior do homem, mesmo que pertençam à sua vida em sociedade." (WIENER, 1968, p.17-18, grifo nosso) 
comunicativo e estratégico (sociologias "compreensivas" e teorias dos sistemas estruturalistas e funcionalistas, e interacionismo simbólico) que admitem o sentido como conceito fundamental, figuram como concepções conceituais chave para a gramática da informação nos usos sociais da linguagem.

A plurifuncional teoria dos sistemas de Niklas Luhmann demonstra nitidamente a aproximação da teoria dos sistemas às dinâmicas informacionais entre sistema e entorno e como este "intercâmbio" é carregado de um sentido configurador das relações sociais ${ }^{18}$. A informação seria algo como um transfer - "por información se entiende un tránsfer desde el entorno"; contudo, adquiriria a sua força de sentido sistêmica através da seletividade e do "acoplamento estrutural" do sistema, isto é, no contexto do acoplamento estrutural do sistema - sistema e entorno - a informação é "un acontecimiento que se lleva a efecto por una operación que se efectúa en el sistema mismo." (LUHMANN, 2002, p. 106) Por meio desta operação de seletividade do sistema que Luhmann aproxima o sentido da informação ${ }^{19}$.

Informação e sentido estão diretamente associados à concepção de sociedade (ação social). Trata-se de reconstruir esta relação, todavia, preservando o potencial conceitual representativo da construção luhmaniana. Para tanto, vejamos o que diz Luhmann, em específico, sobre sentido e informação.

El hecho de que el sentido se experimente siempre como información o como acción: de nuevo!, selección de posibilidades. Desde esta definición del sentido se hace comprensible por qué tenemos que pagar por nuestro mundo con inestabilidad o con incertidumbre. (LUHMANN, 2002, p. 179, grifo nosso)

La información no es la exteriorización de una unidad, sino la selección de una diferencia que conduce a que el sistema cambie de estado y que, por consiguiente, se opere en él otra diferencia. Cada sistema produce la información y esto en dos sentidos que ya han sido expuestos en lecciones anteriores: a) el carácter de sorpresa de la información y b) la selección de las posibilidades que la información efectúa. El que alguien exprese una

\footnotetext{
18 “Apertura significó comercio con el entorno, tanto para el orden biológico como para los sistemas orientados hacia el sentido (sistemas psíquicos, sistemas sociales...). Surgió así un nuevo énfasis en el modelo: el intercambio. Para los sistemas orgánicos se piensa en intercambio de energía; para los sistemas de sentido, en intercambio de información. Estos sistemas, por decirlo de alguna manera, interpretan el mundo (bajo la disposición de la energía o de la información) y reaccionan conforme a esa interpretación. La entropía en ambos casos obliga a que los sistemas establezcan un proceso de trueque entre sistema y entorno." (LUHMANN, 2002, p. 47, grifo nosso)

19 "La operación que describe la maniobra operativa de la autorreferencia y heterorreferencia devela la existencia de una esfera específica de la realidad: el sentido. Tanto la representación fenoménica del mundo, como la información referida a procesos de sentido contenida en las estructuras de la comunicación, ponen de manifiesto la existencia de estructuras de sentido que quedan a la disposición de cada una de estas operaciones, aunque sobre la base de distintos fundamentos operacionales que es necesario aclarar." (LUHMANN, 2002, p. 73, grifo nosso)
} 
proposición es ya una selección en un horizonte inmenso de posibilidades de expresión. Una noticia deportiva está necesariamente colocada dentro de un contexto: el futbol no puede ser confundido con el tenis. De aqui que los horizontes de selección ya están predefinidos. La información, así, necesita llevarse a cabo en un contexto de expectativas, para luego, sobre esa banda de posibilidades, lograr una selección. El que la información sea selección en una escala de posibilidades, es un argumento muy fuerte para asegurar la tesis de que la información sólo puede llevarse acabo en el sistema de comunicación. Sólo allí se crea el contexto de las expectativas y sólo allí la información es uma sorpresa. La información como tal es lo que precisamente antecede y postcede a la irritación y que sólo se logra en el contexto de un sistema. (LUHMANN, 2002, p. 222, grifo nosso)

Como contraponto à perspectiva luhmaniana, a virada interpretativa flexionada pela guinada pragmático-linguística, tratará num primeiro momento, nas cercanias de uma hermenêutica radicalizada, da linguagem como "abertura do mundo" (HEIDEGGER, 2010) e mais adiante, no programa hermenêutico reconstrutivo habermasiano, das práticas linguísticas socialmente estruturadas como o que "franqueiam o mundo nas perspectivas de costumes e tradições fundadoras de sentido. " (HABERMAS, 2007, p. 45, grifo nosso). À diferença do observador - figura fundamental para a perspectiva objetivadora ${ }^{20}$ - está o intérprete - aquele que "entende o significado, assume sua experiência fundamentalmente como participante de uma comunicação, sobre a base de uma relação intersubjetiva. " (HABERMAS, 1998, p. 29) Ou seja, em contraste à perspectiva da sociedade como "un sistema clausurado en su operación", Habermas (2010a, p. 190) dirá que a sociedade é, em um primeiro instante, "tecida de redes de interações mediadas pela linguagem" que franqueiam o mundo em sua faticidade e validade, e, por conseguinte, "a sociedade compõe-se das ordens legítimas através das quais os participantes da comunicação regulam a sua pertença a grupos sociais e asseguram a solidariedade. " (HABERMAS, 2010a, p. 202, grifo nosso). Tão logo, esta perspectiva postula uma possível aproximação da relação da informação com as ciências reconstrutivas, conforme o princípio de que,

Qualquer ciência que admita objetivações de significados como parte da sua área temática tem de se haver com as consequências metodológicas do papel do participante de um intérprete que não só "dá" significado aos objetos observados, mas que tem de explicar o significado "dado" de objetivações que apenas podem ser compreendidas a partir do interior de processos de comunicação. (HABERMAS, 2010a, p. 301)

\footnotetext{
${ }^{20}$ Conforme Luhmann (2002, p. 112): "Todo lo dicho es dicho por un observador [...] Sólo podemos tener acceso a las cosas objetivas del mundo mediante información, a través de lo que los otros dicen y, por supuesto, de lo que nosotros decimos. Pero en la sociedad moderna siempre está a disposición el recurso de la observación y esto como una forma de crítica que siempre debe uno aplicarse a sí mismo." E neste mesmo trecho, um pouco mais acima, afirma que toda a descrição do mundo conforme a teoria dos sistemas "es un esquema referido a un observador."
} 
A informação não somente precede e sucede uma "irritação", ou, numa revisão reconstrutiva da pragmática formal, um discurso. Como algo que antecede e sucede ao discurso, a informação teria um estatuto "dado" pelas significações objetivadas do mundo aberto pela linguagem, isto é, habitaria o espaço linguisticamente estruturado, précompreensivo, pré-reflexivo, de um saber não tematizado, assegurado por um pano de fundo consensual do mundo da vida. Nesta instância estabilizada por acordos discursivos de outrora e garantida pelas tradições culturais, a informação associar-se-ia com a construção social do conhecimento $^{21}$ - “informação como conhecimento comunicado". (CAPURRO; HJØRLAND, 2007, p. 162). Todavia, quando as pretensões de validade de um saber são criticizadas e postas em questão, abre-se uma esfera discursiva para numa dimensão cognitivo-comunicativa, solucionar os eventuais problemas identificados e num processo de aprendizagem formador do mundo, comunicativamente aprender com o outro. ${ }^{22}$

Em 1952, de modo seminal, Harold Garfinkel, que posteriormente apresentaria, no ramo das sociologias compreensivas, a etnometodologia, escreveu Toward a sociological theory of information como um esforço de re-humanização dos estudos da informação. Ainda que não se refira explicitamente à Wittgenstein em sua obra, Garfinkel apresenta uma série de ideias conexas ao pensamento do filósofo alemão - que nos associamos em abordagem -, todavia, chamando a atenção para o papel "constitutivo" - conforme as teorias constitutivas da sociedade ${ }^{23}$ - da informação para uma concepção da sociedade. Deste modo, argumenta Garfinkel (2008, p. 113) acerca do seu procedimento metódico: "We know the thing 'information' through usage. We're looking for the ideas that are immanent to the concept of

\footnotetext{
21 "Poderíamos dizer que aquilo designado nas modernas sociedades ocidentais como conhecimento teria como traço principal a demanda de objetividade, oferecendo alguns critérios e procedimentos de prova e alguma 'garantia' ou princípio de justificação que dê conta de sua legitimidade. O aferimento de seu desempenho terá assim como ponto de partida uma dupla referência: a um domínio de legitimação e a um domínio de intervenção. Como forma intencional de ação (que implica definir ao menos qual seja o conhecer que propriamente conhece, o que é aquilo a ser conhecido e quem é o conhecedor desse conhecimento), seria esperado de uma esfera de produção de conhecimentos que toda afirmação possa ser negada, refutada, modificada e que sempre seja possível tematizar e questionar as condições e procedimentos de validação." (GONZÁLEZ DE GÓMEZ, 1999, p. 21, grifo nosso).

22 "Nos contextos de ação nos informamos ou nos transmitimos informações sobre os objetos da experiência. Certamente que o conteúdo da informação se apoia nos fatos, mas é só quando a informação se coloca em dúvida e passa a discutir-se acerca do conteúdo dessa afirmação desde o ponto de vista da possibilidade de que algo seja o caso, mas pudesse também não sê-lo, falamos de 'fatos', que (ao menos) um 'proponente' afirma e que (ao menos) um oponente põe em dúvida.' [...] No contexto da ação a informação tem o papel de uma afirmação acerca de uma experiência com objetos, no discurso cumpre a função de uma enunciado com pretensão de validade problematizada. [...] Nos contextos de ação posso equivocar-me em minha experiência com os objetos [expectativa e antecipação de resultados], nos discursos tenho ou não tenho razão no que toca a pretensão de validade que afirmo para meu enunciado." (HABERMAS apud GONZÁLEZ DE GÓMEZ, 2009, p. 120)

23 "For Garfinkel, ultimately, constitutive order = meaning (and oriented objects) and therefore, constitutive orders = information, which is possible only against a background of constitutive expectation." (RAWLS, 2008, p. 30, grifo nosso)
} 
information in use, and we seek to isolate these ideas and arrange them in rational fashion." Anne Warfield Rawls (2008, p. 56) na introdução ao livro de Garfinkel afirma que em 1952, esta ideia, aplicada a este contexto, é inovadora. Argumenta Rawls (2008, p. 48) por meio do pensamento de Garfinkel "is social patterning that gives things and information meaningful and public form." A informação na teoria compreensiva de Garfinkel somente pode ser aferida através das relações ordenadas que a constitui. Frente ao dilema ${ }^{24}$ da informação como produto da experiência em contraposição à informação como experiência atemporal das coisas, Garfinkel argumenta que a informação não é somente experiência significativa, é também, uma experiência decisória (seletiva) de julgamento: "information is a judgment" (GARFINKEL, 2008, p. 168). Isto é, a concepção social da informação em Garfinkel implica uma validação discursiva interpares: "I experience it with one sense attached to it as a determining sense, namely, the sense of the judged thing. We have then our first specification of the thing, 'information', I experience it not as liked, loved, hated, wished for, doubted, but judged." (GARFINKEL, 2008, p. 158, grifo nosso) Não se trata mais das coisas dadas naturalmente ou por via de uma linguagem natural, versa-se, sobretudo de enxergar a informação como uma ação relacional (GONZÁLEZ DE GÓMEZ, 1995; 1999; 2006), ou, nas palavras de Garfinkel (2008, p. 108), "Information is relationships not things" 25 .

A posição de Garfinkel é de extrema pertinência para uma reconstrução racional das redes interativas de informação. A dinâmica de sentido e validade nas pretensões do que possa vir a ser concebido como informação é um ponto chave para o entendimento de uma sociedade predicada como informacional. Contudo, Garfinkel, de acordo com as argumentações e justificações teórico-práticas do eixo das sociologias compreensivas e suas respectivas abordagens constitutivas da sociedade, vincula-se à perspectiva da razão centrada no sujeito. A "microsociologia" de Garfinkel ainda se encontra unida à figura do "ego

\footnotetext{
24 "What I'm after is somehow to resolve the bothersome dilemma between information as a momentary product of experience and information as an atemporal sum of things experienced." (GARFINKEL, 2008, p. 158)

25 "[...] the idea that information does not transmit events - but a patterned relationship between events. The 'thing' is not the information. Information is the relationship between the thing and other possibilities. This also necessarily invokes a more social approach because relationships are between things. They are not actual things. Therefore, they are either interactive or conceptual; socially patterned relationships between events. The social is exactly what information is on this account. Furthermore, social 'things' exist as things only in and through their relationship to a whole fabric of social relationships in and through which they are constituted just like information. Something must remain constant across these events that are not the thing - but still somehow information about the thing. The constant is the pattern. This is another way that the social begins to get into information theory - in addition to theories of language." (RAWLS, 2008, p. 41, grifo nosso)
} 
constituinte", de um Eu que experiencia o espaço e o tempo social através de uma subjetividade universalmente realizadora ${ }^{26}$.

Com o objetivo de não perder o fio argumentativo de Garfinkel acerca da questão da informação enquanto algo enredado de normatividade, esta se aproximaria ao modelo democrático deliberativo, como referido no projeto reconstrutivo de Seyla Benhabib, diretamente associado à teoria crítica reconstrutiva e à perspectiva habermasiana: "[...] deliberative processes are also processes that impart information. New information is imparted because 1) no single individual can anticipate and foresee all the variety of perspectives through which matters of ethics and politics would be perceived by different individuals", e continua, complementando, "no single individual can possess all the information deemed relevant to a certain decision affecting all. Deliberation is a procedure for being informed." (BENHABIB, 1996, p. 71) Seyla Benhabib, nesta assertiva acerca do processo deliberativo, indica que foi influenciada pelo "excellent article" On Legitimacy and Deliberation, de Bernard Manin, onde este trata de analisar histórica e conceitualmente o conceito de deliberação e legitimidade, além de focar na sua dinâmica procedimental. Por meio desta conceituação de Seyla Benhabib, os plexos acionais informativos passam da esfera das teorias constitutivas da sociedade, focada na razão centrada no sujeito, para o plano normativo intersubjetivo das teorias comunicativas da sociedade. Acerca dos processos deliberativos, diz Bernard Manin (1987, p. 351-352):

The process of deliberation, the confrontation of various points of view, helps to clarifity information [...] the aim of the deliberative process is to broaden the participants' information and enable them to discover their own preferences, that process requires a multiplicity of points of view and/or arguments. [...] Thus deliberation tends to increase information.

Logo, quando Maria Nélida González de Gómez (1999, p. 13) fala de uma "nova ontologia da informação", não se trata de uma essência ou forma supramundana, como no modo ontológico clássico da informação enquanto "dar a forma a algo", mas de uma perspectiva pós-metafísica, onde "a essência se expressa na gramática”, sendo a gramática que diz "que espécie de objeto uma coisa é” (WITTGENSTEIN, 2008, §371-373, p. 158) em seus diferentes domínios de referência. Rafael Capurro (1992) em seu clássico texto What is

\footnotetext{
${ }^{26}$ Para desdobramentos desta crítica feita pela comunidade de pares à Garfinkel, ver a admissão da crítica e uma possível defesa de Garfinkel feita por Rawls (2008, p. 56). Habermas (2010a, p. 47) direciona sua crítica a Garfinkel nestas palavras: "os sujeitos sociais movem-se nos seus processos de consciência constitutivos da sociedade no mesmo plano transcendental em que o sujeito cognoscente constitui a natureza como objeto de possíveis experiências."
} 
information science for? A philosophical reflection aponta para informação, em seu sentido hermenêutico-retórico, como uma cópula que significa temática e situacionalmente compartilhar um mundo comum. Deste modo, são postulados ontológicos da linguagem:

[...] um "mundo" não só para o que é "objetivo" e que encontramos numa atitude de terceira pessoa [ele], mas também um mundo para o que é "normativo" e ao qual nos sentimos obrigados na qualidade de destinatários [tu], assim como um mundo para o que é "subjetivo" e que nós desvendamos ou escondemos na qualidade de primeira pessoa [eu], perante um público. Em cada ato de fala o locutor refere-se simultaneamente a algo no mundo objetivo, num mundo social comum e no seu mundo subjetivo. [...] É também necessário submeter a um alargamento correspondente o conceito fenomenológico, trabalhado especialmente por Heidegger, de um contexto referencial de um mundo da vida, que forma o contexto indubitável do processo de compreensão, por detrás dos participantes na interação. Os participantes já não vão buscar a este mundo da vida somente os padrões consensuais de interpretação (o saber de base do qual se alimentam os conteúdos proposicionais) mas também os padrões de relações sociais de confiança no plano normativo (as solidariedades tacitamente implícitas em que se apoiam os atos elocutórios) e as competências adquiridas no processo de socialização (o pano de fundo das intenções do locutor). [...] A razão comunicacional expressa-se num entendimento descentrado do mundo. (HABERMAS, 1998, p. 290-291)

As regras gramaticais ordenadoras dos mundos objetivo, social e subjetivo visam a finalidade da linguagem $(2008, \S 497$, p. 186) -, isto é, o entendimento. Entender-se com alguém sobre algo, esta seria a finalidade da linguagem em suas múltiplas formas de vida: “"Assim você está dizendo, portanto, que a concordância entre os homens decide o que é certo e o que é errado?' - Certo e errado é o que os homens dizem; e os homens estão concordes na linguagem. Isto não é uma concordância de opiniões mas da forma de vida. " (WITTGENSTEIN, 2008, §241, p. 123, grifo nosso

Quando a associação da informação ao plano hermenêutico do sentido ${ }^{27}$ se dá via pragmática formal, não se estreita e reduz a capacidade de significação aos planos de coordenação sistêmica nem, por conseguinte, amplia a capacidade interpretativa ao ilimitado/indeterminado - como na hermenêutica radical. No plano da pragmática formal, o “significado é uma noção normativa” (OLIVEIRA, 2012, p. 153), “o significado de um

\footnotetext{
27 "La información es algo que está más allá de los datos, de los símbolos, los cuales como envoltura material la acompañan. Esta posición nos recuerda las ideas de Frege (su división de lo objetivo real, ló subjetivo y lo objetivo no real); de Popper con su teoría del tercer mundo, y de Husserl que nos hablan del mundo de los eidos. [...] A este reino [do objetivo não real] pertenecen los pensamientos, los cuales pueden captarse, poseerse y comunicarse intersubjetivamente. Ahora bien, si aceptamos que el pensamiento no es vacío, sino que tiene información (o si se quiere, para simplificar, es información) entonces existe el mundo objetivo no real de la información." (RENDÓN ROJAS, 2005, p. 90-91)
} 
produto simbólico não pode independer da validade que the é atribuída" (REPA, 2014, p. 469), isto é, orienta-se por regras racionais, o que leva Habermas (2010a, p. 304) a dizer que no âmbito das ciências reconstrutivas, "todas as interpretações são interpretações racionais. " Está claro que o pano de fundo de referência de todos estes autores é o "seguir a regra"28 wittgensteiniano e, em comunhão a isto, aquilo que é indagado pelos procedimentos das ciências da reconstrução, "não são estes ou aqueles objetos em particular, mas as regras, as estruturas, os critérios de avaliação e os processos sociais mais amplos em que determinados objetos simbólicos se inserem e ganham um sentido social e racional, que é alvo da teoria reconstrutiva. " (NOBRE; REPA, 2012, p. 18)

Interpretar é representar uma regra. O significado, segundo Wittgenstein, não se dá através do uso privado da razão ou de uma cadeia de interpretações concebidas internamente. Seguir uma regra é significar uma prática, interpretar é aprender a usar os jogos de linguagem construídos intersubjetivamente pelos usos sociais da razão. Assim aconselha Wittgenstein (2008, p. 276): "deixe que o uso lhe ensine o significado."

Ao seguir regras adota-se uma atitude normativa transubjetiva - para além do indivíduo, dos estados mentais psicológicos - que leva em conta toda dimensão institucional da linguagem e de seus atores - "são as esferas normativas da rede comunicativa que garantem a interação" (HABERMAS, 1983, p. 15). Seguir a regra é uma atitude semânticopragmático. Significar é uma ação social que pressupõe usos, aprendizagem e treinamento, inerentes às formas de vida situadas. Em uma perspectiva reconstrutiva racional, a normatividade está implícita em qualquer processo de significação.

[...] a normatividade intrínseca do significado é o que nos permite tornar explícito o significado das premissas implícitas em inferências (dedutivas) quando, por exemplo, usamos conceitos cujo conteúdo é a atribuição de conteúdo conceitual, visto que a linguagem é e deve ser pública. O critério de correção é externo, pois a única maneira de decidir pela correção ou incorreção do uso de uma expressão é através da suposição de que existem outros usuários da linguagem que compartilham os mesmos significados e, que, portanto, são capazes de indicar se o uso é adequado ou não. (OLIVEIRA, 2012, p. 161, grifo nosso)

\footnotetext{
28 "Com isso mostramos, a saber, que há uma concepção de regra que não é uma interpretação; mas que se exprime, de caso para caso da aplicação, naquilo que denominamos 'seguir a regra' e 'transgredi-la'. Por isso, existe uma tendência de dizer: todo agir de acordo com a regra é uma interpretação. No entanto, dever-se-ia denominar 'interpretar' somente: substituir uma expressão da regra por outra expressão.

Por isso, 'seguir a regra' é uma prática. E acreditar seguir a regra não é: seguir a regra. E por isso não se pode seguir a regra 'privatim', porque, do contrário, acreditar seguir a regra seria o mesmo que seguir a regra." (WITTGENSTEIN, 2008, § 201-202, p. 113-114, grifo nosso)
} 
Conforme o ensinamento de Wittgenstein, a partir dos processos intersubjetivos regulados pelas gramáticas das formas de vida nos deparamos com o sentido. Lá aonde na escavação pelo saber a "pá entorta", ou, os ramos da árvore do conhecimento assemelham-se ao caule, neste lugar, nos defrontamos com o sentido.

'Como posso seguir uma regra' - se esta não é uma pergunta pelas causas, então é uma pergunta para justificar minha maneira de agir de acordo com a regra. Se esgotei as justificativas, cheguei então à rocha dura, $\mathrm{e}$ minha pá se entorta. Estou inclinado a dizer então: 'É assim mesmo que ajo.' (WITTGENSTEIN, 2008, § 217, p. 118)

'Tem que ser indestrutível o que os nomes da linguagem designam: pois deve-se poder descrever o estado no qual é destruído tudo o que é destrutível. E nesta descrição haverá palavras; e o que lhes corresponde não pode ser destruído, caso contrário as palavras não teriam significado algum.' Não posso serrar o galho sobre o qual estou sentado.

Com efeito, poder-se-ia objetar de imediato que a descrição mesma tem que excetuar-se da destruição. - Mas o que corresponde às palavras da descrição e, portanto, não pode ser destruído, se ela for verdadeira, é o que dá às palavras o seu significado - sem o que elas não teriam significado algum. - Mas este homem de fato é, em certo sentido, o que corresponde ao seu nome. Mas é destrutível; e seu nome não perde o significado quando o portador é destruído. - O que corresponde ao nome, e sem o que ele não teria significado algum, é, por exemplo, um paradigma que é usado no jogo de linguagem em ligação com o nome. (WITTGENSTEIN, 2008, §55, p. 46, grifo nosso).

A hermenêutica reconstrutiva situa-se no entroncamento entre duas perspectivas complementares de usos da linguagem. Jürgen Habermas (2010a) argumenta que por meio da pragmática formal, o entendimento do uso cognitivo e do uso comunicativo da linguagem habilita a reconstrução da passagem da teoria da constituição à teoria da comunicação da sociedade $^{29}$.

A palavra "uso" aqui é uma assinatura da reviravolta linguístico-pragmática da filosofia contemporânea ${ }^{30}-$ em especial, da teoria do uso do significado ${ }^{31}$. No contexto da

\footnotetext{
29 "O uso comunicativo da linguagem pressupõe de igual forma o uso cognitivo da linguagem, através do qual dispomos de conteúdos proposicionais; como também, de modo inverso, o uso cognitivo da linguagem pressupõe o uso comunicativo da linguagem, visto que frases assertórias podem apenas ser utilizadas em atos de fala constativos. Uma teoria de comunicação da sociedade, embora se dirija de forma imediata a sedimentações e produtos do uso comunicativo da linguagem, tem de adequar-se à dupla estrutura cognitivocomunicativa do discurso." (HABERMAS, 2010a, p. 95, grifo nosso)

${ }^{30}$ Uma interessante passagem acerca da linguistic turn em associação à teoria da informação como uma das forças motrizes desta guinada é feita por Rawls $(2008$, p. 3): "[...] information raises the classic problem of language and meaning in a new and very pragmatic form. Thus, from the beginning, information theory has addressed deep philosophical issues of epistemology and ontology and has been closely tied to theories of language. In fact, this may have been one of the driving forces behind what has been called the "linguistic turn" in modern scholarship."

${ }^{31}$ Aqui a referência é o livro "Investigações filosóficas" do segundo Ludwig Wittgenstein. Na prática do uso da linguagem onde todo processo de uso de palavras configura-se um jogo linguagem - isto é, uma linguagem
} 
argumentação de Habermas (2010a, p. 73-96) essa guinada marca a passagem das teorias da constituição da sociedade, com enfoque nas abordagens da filosofia da consciência e seus respectivos "atos de consciência", "atos intencionais" pré-figurados por uma subjetividade que representa o mundo em seu todo, sendo a(s) sociedade(s) uma "individualidade coletiva" para as teorias da comunicação da sociedade, baseadas na filosofia pragmática da linguagem e suas respectivas ações sociais (comunicativas, estratégicas) pré-figuradas pelo princípio de um mundo intersubjetivo partilhado por sujeitos socializados, sendo a(s) sociedade(s) um contexto de vida estruturado através de forma(s) de vida dotada(s) de sentido, ou nos termos de Habermas (2010a, p. 201) "mundo da vida simbolicamente estruturado".

Os dois planos da linguagem, cognitivo e comunicativo, estão integrados e movem-se por meio do meta-plano hermenêutico do uso da linguagem orientado ao entendimento cuja pretensão de validade é a compreensibilidade. $\mathrm{O}$ uso cognitivo da linguagem faz referência a algo no mundo, utiliza-se da função representativa da linguagem, tendo por propósito transmitir algo sobre uma realidade objetivada; em geral, seu sentido está vinculado às enunciações constativas, afirmativas, explicativas que remetem às pretensões de validade da verdade acerca de um mundo culturalmente objetivado. $\mathrm{O}$ uso comunicativo da linguagem atua na dimensão intersubjetiva dos locutores que agem com referência a algo no mundo com o intuito do entendimento interpessoal; em geral, os usos comunicativos acontecem em dois planos de sentido e validade: a) da expressão, tendo por pretensão de validade a sinceridade e a honestidade dos locutores e b) o normativo, tendo por pretensão de validade a correção das normas e das regras das gramáticas dos jogos de linguagem aceitos. Dito isso, reforça Habermas (2010a, p. 95), acerca da "dupla estrutura cognitivo-comunicativa do discurso" da teoria da comunicação da sociedade: "o uso comunicativo da linguagem pressupõe de igual forma o uso cognitivo da linguagem [...] como também, de modo inverso, o uso cognitivo pressupõe o uso comunicativo da linguagem. ” A argumentação acerca desta dupla estrutura interdependente dos usos da linguagem perante o mundo, forma gramatical elementar do discurso.

primitiva cotidiana. "Chamarei de 'jogo de linguagem' também a totalidade formada pela linguagem e pelas atividades com as quais ela vem entrelaçada. [...] Quando a criança aprende esta linguagem [...] ela tem que aprender o seu uso. [...] Imagina-se como se poderia ensinar seu uso! Aponta-se para lugares e coisas - mas aqui este apontar acontece também no uso das palavras e não só no aprendizado do uso." (WITTGENSTEIN, 2008, § 7-8, p. 19-20, grifo nosso). Assim fica circunscrito que a referência a algo no mundo (denotação) não mais é entendida como uma região semântica, um conjunto - no sentido formal e matemático do termo - de todas as possibilidades, por exemplo, do sentido de uma palavra, mas que este sentido é aprendido através da validade dos usos ordinários da palavra - "[...] 'referência', isto é, o uso dessas palavras." (WITTGENSTEIN, 2008, §10, p. 20) 
Portanto, a partir deste meta-plano estruturado pelos usos ordinários da linguagem, a questão semântico-pragmática da informação ascende camaleonicamente com novas cores, pois com novos cenários, e ancora-se nos usos cognitivos e comunicativos da linguagem e em seus processos implicados de sentido e validade.

\section{Reconstrução racional, um método da teoria crítica}

Tão logo apresentadas essas coloções acerca do estatuto reconstrutivo da informação e sua ancoragem nas categorias fundamentais de sentido e validade, torna-se cada vez mais premente a sistematização do que se entende sobre a teoria da reconstrução racional enquanto uma via alternativa para teoria crítica da sociedade contemporânea. Esta questão motivadora à reconstrução racional enquanto meta-teoria (HABERMAS, 1983, p. 208) toca a ciência da informação a partir da estrutura conjuntural que levou nos anos 1970 à denominação da sociedade como informacional. É no relatório The information economy: definition and measurement, redigido por Marc Uri Porat no United States Departament of Commerce em 1977, que surge o termo information society. (PORAT, 1977) A sistematização do que seria a sociedade da informação estaria caracterizada pela conjunção das forças produtivas inovativas manifestadas pela nova dinâmica material da economia: a informação. Logo, seriam através de conceitos como information ${ }^{32}$, information activity ${ }^{33}$, information capital $^{34}$, information workers $^{35}$, information goods and services ${ }^{36}$ que se moveria a estrutura desta sociedade, ou, em outras palavras, o princípio de organização da sociedade da informação, para Marc Porat e uma horda de seguidores, estaria baseado na relação entre "the information workers and the information capital" (PORAT, 1977, p. 20), assim como Marx tinha mostrado que o princípio de organização capitalista estava baseado na relação trabalho assalariado e capital.

Ficam algumas evidências analíticas: a) a sociedade da informação é um incremento "evolutivo" no quadro da dinâmica material do capitalismo; b) a inclusão sistêmica da informação no tecido dessas relações materiais implica, ao menos duas consequências: b.a) um aumento considerável na capacidade de direção e controle das relações a partir do

\footnotetext{
32 "Information is data that have been organized and communicated." (PORAT, 1977, p. 19)

33 "The information ativity includes all the resources, consumed in producing, processing and distributing information goods and services." (PORAT, 1977, p. 19)

34 "typewriters, calculators, copiers, terminals, computers, telephones and switchboards" (PORAT, 1977, p. 19)

35 "[...] research scientist, engineer, designer, draftsman, manager, secretary, clerk, accountant, lawyer, advertising manager, communications officer, Personnel director - all essentially paid to create knowledge, communicate ideas, process information - in one way or another transform symbols from one form to another. (PORAT, 1977, p. 20)

36 “telecommunications, business consulting, legal advice, paper and office supplies". (PORAT, 1977, p. 20)
} 
potencial organizativo e ordenador da informação, b.b) um aumento na capacidade comunicativa entre os sistemas parciais da sociedade, concebida por meio de um princípio econômico funcional onde a "information' to denote the process or activity", como afirma Fritz Machlup (1984, p. 5) pesquisador que desde os anos 1960 apontava para uma economia da informação. Ou seja, a concepção do tecido social por Porat a partir do medium informação objetiva descrever um novo modo de integração sistêmica - "medida das capacidades de controle e aprendizagem de um sistema em relação às necessidades de direção e controle que, em cada oportunidade concreta, surgem em relação a um ambiente complexo" (HABERMAS, 1983, p. 183) - regida de maneira primaz pela informação. Todavia, esta sociedade da informação descrita pelas justificações monológicas da economia não dá conta da multidimensionalidade de um mundo vivido hipercomplexo carregado de interações solidárias anteriores às mediatizadas relações do dinheiro e do poder. É acerca das dificuldades e potenciais teórico-práticos da sociedade da informação, ou dos tecidos comunicativos que têm na dimensão informacional certa evidência fulcral da época contemporânea, que o programa da reconstrução racional se apoiaria em sua orientação para emancipação. (NOBRE; REPA, 2012, p. 17)

\begin{abstract}
Reconstruir não significa reproduzir o que é factualmente, mas refletir sobre as regras que têm de ser supostas para que seja possível a própria compreensão do sentido e mesmo do não sentido do que é construído social e simbolicamente. Ao mesmo tempo, são regras, estruturas e processos que mostram potenciais de emancipação, possibilidades melhores de desenvolvimento, que não podem ser reduzidos à realidade existente, à facticidade de contextos que podem significar, ao contrário, $\mathrm{o}$ bloqueio dessas potencialidades emancipatórias. (NOBRE; REPA, 2012, p. 8 , grifo nosso)
\end{abstract}

A reconstrução é uma alternativa aos modelos de reflexão transcendental e dialéticos ${ }^{37}$. Focalizada nas regras, estruturas, critérios de avaliação e processos sociais mais amplos em que determinados objetos simbólicos se inserem e ganham sentido, a reconstrução “identifica e fundamenta os critérios normativos da crítica, a qual se refere a um diagnóstico de época que se vale desses critérios para localizar processos de dominação e potenciais de emancipação. " (REPA, 2014, p. 468) A reconstrução racional baseia-se na "forma do diálogo e é discutida na forma de diálogo, mas não pode prescindir de um momento objetivante em que se afirma algo sobre o mundo" (REPA, 2014, p. 470). Trabalho e interação são categorias fundamentais à reconstrução - "somente nas estruturas de trabalho e linguagem

\footnotetext{
${ }^{37}$ Para o conhecimento das dificuldades teórico-práticas destes modelos ver, ao menos, Repa (2008; 2014) e Voirol (2012).
} 
completaram-se os desenvolvimentos que levaram à forma de reprodução da vida especificamente humana e, com isso, à condição que serve como ponto de partida da evolução social", e conclui Habermas (1983, p. 118), "trabalho e linguagem são anteriores ao homem e à sociedade. " Dito isso, concordamos com as interpretações de Pedersen (2008) e Nobre e Repa (2012) quando partilham a reconstrução racional em dois ramos: 1) a pragmática-formal como reconstrução sincrônica horizontal e 2) a teoria da evolução social como reconstrução diacrônica vertical, possuindo a evolução social 2.1) uma lógica evolutiva da aprendizagem e 2.2) uma dinâmica evolutiva material.

A pragmática formal postula reconstruir as condições de possibilidade do entendimento mediado pela linguagem, isto é, o sistema das regras que possibilitam o acordo entre sujeitos socializados linguisticamente. Seria tarefa da teoria da linguagem "localizar e reconstruir as estruturas gerais da forma de vida comunicativa na pragmática universal dos jogos de linguagem enquanto tais. "(HABERMAS, 2010a, p. 97)

As duas peças teóricas centrais da pragmática formal são os usos cognitivos e comunicativos da linguagem, operadores reconstrutivos da maior postuladora de universalidade da espécie: a competência comunicativa humana ${ }^{38}$. Seria esta capacidade de falar e agir (interação e trabalho, simbolização e instrumentação, comunicação e informação) que facultaria à raça de hominídeos uma distinção da natureza ${ }^{39}$; esta capacidade configura uma "competência ideal para regras", para a atribuição de sentido e validade dos atos de fala da descomunal esfera da vida. A esta competência linguística, se debruça a pragmática formal, sendo seu "fenômeno-chave" a "reflexividade das linguagens naturais." (HABERMAS, 2010a, p. 103)

A competência comunicativa de um falante ideal não somente inclui a capacidade de produzir e entender orações gramaticais, todavia, também, implica a capacidade de estabelecer e entender esses modos de comunicação e conexões com o mundo externo, mediante a possibilidade de fala promovida pela fonte recursiva da linguagem ordinária. Em

\footnotetext{
38 “Uma situação de entendimento possível exige pelo menos dois locutores / ouvintes estabeleçam em simultâneo uma comunicação em dois planos: no plano da intersubjetividade em que os sujeitos falam uns com os outros, como no plano dos objetos (ou estado de coisas) sobre os quais se entendem. A pragmática universal destina-se à reconstrução do sistema de regras que um locutor competente tem de dominar se quiser poder satisfazer esse postulado (da simultaneidade da comunicação e da metacomunicação). Para esta qualificação gostaria de reservar a expressão da 'competência comunicativa'." (HABERMAS, 2010a, p. 104, grifo nosso)

39 “El habla es el médio distintivo y omnipresente de la vida en el nível humano, la teoría de la comunicacíon constituye la disciplina universal y básica de las ciencias humanas; revela la infraestrutura universal de la vida sociocultural." (McCARTHY, 2013, p. 327, grifo nosso) E em outra passagem, McCarthy (2013, p. 333, grifo nosso) argumenta: "Aquello que nos separa de la naturaleza es la única cosa que podemos conocer en su naturaleza: el lenguaje."
} 
contraste com a pragmática empírica, investigadora das condições limitadoras, empíricas e contingentes da comunicação efetiva e da gramática que implica regras para geração de orações em qualquer língua, a pragmática formal mira as regras para uma situação qualquer dos atos de fala, não específicas de um contexto "x" e sem referência a uma gramática generativa universal que hipoteticamente mira a competência linguística numa capacidade inata para a linguagem, pois, ao inverso desta, a competência de que fala a pragmática formal está diretamente vinculada ao processo de aprendizagem evolutivo da espécie fundado na socialização dos discursos informativos e comunicativos, cognitivos e práticos ${ }^{40}$, isto é, faz parte do processo de desenvolvimento formativo do gênero humano.

Em face desta dimensão do saber não tematizado e das estruturas locucionais generalizadas, Habermas enumera classes exemplares de palavras e respectivas gramaticalizações que se referem às estruturas gerais da situação de fala. A este conjunto denominará universais pragmáticos ${ }^{41}$ ou "universais construtores do diálogo". (HABERMAS, 2010a, p. 115)

A pragmática formal, em seu conjunto familiar de conceitos direcionados à realização de um entendimento (estágio fraco) ou um acordo (estágio forte), diante da expressão da matriz universal da linguagem, e, de certo modo, do gênero humano, em última instância, nos diz: entendemos os atos de fala quando sabemos o que os tornam aceitáveis, isto é, a pragmática formal postula a fundamentação do elo entre sentido e validade.

Passemos à teoria da evolução social como reconstrução diacrônica vertical, subdividida em lógica evolutiva (filogenética) e dinâmica evolutiva (ontogenética). A teoria da evolução social possui um estatuto complementar à pragmática formal, "[...] versa sobre o desenvolvimento das estruturas normativas que tornaram possível o surgimento das sociedades modernas, no núcleo das quais se podem verificar as regras da interação comunicativa." (REPA, 2014, p. 466) Quando Habermas põe em discussão o conceito de estruturas normativas, seja no texto de 1976, Introdução: o materialismo histórico e o desenvolvimento de estruturas normativas - com a classificação "estruturas da intersubjetividade, estruturas da normatividade, estruturas da subjetividade" (1983, p. 167) -, ou no texto de 1985, O conteúdo normativo da modernidade, neste último com as designações

\footnotetext{
40 "A teoria da evolução não encontra sua aplicação na historiografia, mas sim no discurso prático." (HABERMAS, 1983, p. 167)

41 “1. Pronomes pessoais; 2. Palavras e formulações que são utilizadas para dar início a uma fala e para dirigir a palavra a alguém (gramaticalização: vocativo, honorativo); 3. Expressões dêiticas (do espaço, do tempo); 4. pronomes demonstrativos, artigos, numerais, quantificadores; 5. Verbos performativos; 6. Verbos intencionais sem aplicação performativa, advérbios de modo. [...] Sem referência a esses universais nem sequer podemos definir os componentes recorrentes de situações de fala possível.” (HABERMAS, 2010a, p. 107-108)
} 
"reflexividade, universalismo e individuação" (1998, p. 316), ele intenta estabelecer as estruturas universais sem as quais o mundo da vida não se suportaria. Por estrutura entendase:

[...] sistemas fundamentais de regras, que são observadas no plano do conhecimento, da linguagem e da interação. Essas regras não são diretamente extraídas da superfície dos fenômenos; trata-se, antes, de estruturas profundas a que os indivíduos, criando formações culturais observáveis, se adéquam de modo não intencional. As regras não valem apenas para os indivíduos singulares, mas têm validade coletiva. Ademais, constituem, em cada oportunidade, um sistema que permite produzir relações de transformação entre as manifestações geradas. As estruturas são passíveis de reconstrução racional. (HABERMAS, 1983, p. 148 , grifo nosso)

As "estruturas universais do mundo da vida", além de apontarem para uma validade coletiva demarcadora de uma identidade coletiva $^{42}$, indicam um corpo de relações historicamente transformadoras, que à luz da história das sociedades, aduz os desafios evolutivos enfrentados em seus respectivos processos de aprendizagem. Reconstruir racionalmente uma esfera megadiversa de relações implica reconhecer o processo complexo de aprendizagem que levou à promoção e ao reconhecimento dos sistemas de regras vigentes, em dado momento, ou, à obstrução evolutiva, caracterizada por uma "patologia da aprendizagem" que demarca os ciclos históricos de "regressão forçada" - por exemplo, o fascismo.

Logo, enquanto a lógica evolutiva "deve ser pensada como um processo de aprendizagem, de modo que se pode identificar por que uma etapa é capaz de resolver problemas da etapa anterior, sem perder o saber acumulado dela", a dinâmica evolutiva trata dos "processos factuais que contribuíram para impulsionar ou impedir determinado desenvolvimento estrutural" (NOBRE; REPA, 2012, p. 28), em geral, processos de reprodução material da sociedade. A lógica evolutiva trata do espaço lógico ${ }^{43}$ em que se apresentam e variam os potenciais e os limites das estruturas normativas que organizam o ordenamento da sociedade - sua cultura, instituições, normas -, a dinâmica evolutiva debruçase pelo movimento empírico-material da sociedade, os problemas sistêmicos e os desafios

\footnotetext{
42 “Gostaria de reservar a expressão 'identidade coletiva' para os grupos de referência que são essenciais para a identidade dos seus membros; que são, de certo modo, 'atribuídos' aos indivíduos, não podendo ser por eles escolhidos a bel-prazer; e que têm uma continuidade que vai além das perspectivas biográficas de seus membros. [...] assegura continuidade e reconhecibilidade [...] regula participação dos indivíduos na sociedade." (HABERMAS, 1983, p. 23-26)

${ }^{43}$ Seria neste espaço lógico evolutivo que estariam contidas as características emancipatórias da sociedade, como por exemplo, a universalização (publicidade), a individuação por socialização, o descentramento dos processos de aprendizagem, a autonomia, a reflexão, etc. Tais características figuram como elementos fundamentais para o postulado emancipatório das relações sociais. Os impulsos evolutivos são direcionados à emancipação. (HABERMAS, 1983, p. 208)
} 
evolutivos implícitos, suas expectativas de resolução dos problemas e seus respectivos processos de aprendizagem que levam um ordenamento social para além da esfera cognitiva de resolução de problemas com vistas a um aumento de complexidade ${ }^{44}$.

A análise da dinâmica de desenvolvimento é colocada 'materialisticamente', na medida em que se refere aos problemas sistêmicos geradores de crise no âmbito da produção e da reprodução; e essa análise permanece 'historicamente' orientada, na medida em que deve buscar as causas das mudanças evolutivas em todo o arco das circunstâncias contingentes, a) nas quais sejam adquiridas novas estruturas na consciência individual, que são transformadas em estruturas de imagens do mundo; b) nas quais surjam problemas sistêmicos que ultrapassem a capacidade de direção e controle de uma sociedade; c) nas quais possa ser experimentada e estabilizada a corporificação institucional de novas estruturas de racionalidade; e d) nas quais possam ser exploradas as novas margens de mobilização dos recursos. (HABERMAS, 1983, p. 37)

A sociedade da informação concebida via primado econômico, estaria circunscrita na esfera da dinâmica evolutiva, superdimensionando esta esfera em detrimento das outras esferas da vida tão importantes quanto à econômica. Talvez, uma das expressões mais precisas, baseadas em Machlup e Porat, mas escrita por Kent Hall (1981, p. 143) no primeiro volume do expressivo periódico The information society: an international journal, para esta vertente econômica das sociedades capitalistas avançadas, seja: the economic nature of information, onde a informação teria um papel central na "dinâmica evolutiva" (do desenvolvimento) da sociedade: "The embodiment of information in people, machines, and organizational arrangements accounts for the majority of society's progress", e continua Hall (1981, p. 141) "the importance of information stems not only from its central role in the daily functioning and progress of all societies but from the effects its unusual characteristics have on human behavior and institutional structures and arrangements". É acerca de uma reviravolta nesse tipo de argumento, que se baseia a teoria da evolução social e seus processos de aprendizagem evolutivos; e, seria no bojo desta guinada que poderíamos seguir a intuição hipotética de que a informação não é um conceito circunscrito apenas no eixo das relações cognitivo-estratégico-instrumentais da modernidade clássica, mas, feito um medium

\footnotetext{
${ }^{44}$ Habermas (1983, p. 122) procura mostrar as debilidades da "complexidade" como um critério diretivo da evolução social: a) o conceito de complexidade torna pouco precisas análises comparativas e podem resultar em insolúveis os problemas de um enquadramento global do ponto de vista da complexidade; b) não há uma relação unívoca entre complexidade e conservação da existência, há aumentos de complexidade que se revelam, no plano da evolução, becos sem saída; c) ainda em referência ao nexo de b), a sociedade não tem problemas claramente definidos e objetivamente solucionáveis no que se refere à conservação da existência, a sociedade não pode ser medida em termos de uma taxa de reprodução, como no índice de desenvolvimento humano enquanto sobrevivência física, ou, nas taxa do PIB enquanto reflexo econométrico do que uma sociedade de fato é.
} 
integrativo, ocupa também um lugar no eixo das relações prático-morais da "modernidade neoclássica" que garante as condições de possibilidade de uma ordem material da sociedade.

\section{Conclusão}

Em um programa reconstrutivo, crítico emancipatório de sociedade, não é o capitalismo que garante o bem comum, mas a política, a vida partilhada em comum; este é o foco reconstrutivo para um programa de sociedade cuja esfera da informação manifesta-se como uma dimensão fundamental da existência humana: "Information means the possibility of sharing thematically a common world within specific forms of life. [...] Information, in an existential-hermeneutic sense, means to thematically and situationally share a common world." (CAPURRO, 1992) Não é condição necessária à informação ser apenas um bem econômico ou um insumo técnico infraestrutural (paradigma da produção), nem as relações de produção social da informação coincidirem com as relações de valores do sistema econômico, que, por sua vez, só são universalizáveis diante do princípio organizativo da sociedade capitalista. Ou seja, a regra: as condições materiais determinam as relações de produção, onde o curso acional econômico amalgama-se criando uma zona de indistinção privilegiadamente econômica em relação aos outros cursos acionais ${ }^{45}$, ou, a estrutura econômica assume as condições de produção e controle da evolução social ${ }^{46}$, só é válido para as contingências das sociedades capitalistas. Não se trata de "destino" ou de condições inevitáveis ao agir humano, todavia, antes, versa sobre uma construção histórico-social contingente de formas de vida específicas - ocidentais ${ }^{47}$. Quando Habermas afirma (1998, p. 84): “A produção constitui apenas um objetivo ou um conteúdo passível de regulamentações normativas”, quer nos dizer que, num plano prático-social, onde procuramos questionar o projeto da sociedade informacional, o paradigma cognitivo-instrumental da produção (capital-trabalho) é aporético, não consegue livrar-se dos constrangimentos patológicos de uma razão coercitiva e opressora, onde tudo se dissolve no automovimento da produção; portanto, sem perspectivas

\footnotetext{
${ }^{45}$ Esta tese ilumina as conclusões de Walter Benjamin (1987) e Giorgio Agamben (2004) sobre o estado de exceção como a regra das sociedades contemporâneas.

46 Esta tese inspira as conclusões econômico-materialistas da sociedade: funcional-estruturalismo, neoevolucionismo e materialismo dialético.

${ }^{47}$ Seria nesta instância contingente que a ética demarcaria o seu contraponto à vigência do espírito naturalizador do capital, segundo Agamben. "O facto de onde deve partir todo o discurso sobre a ética é o de que o homem não é nem terá de ser ou de realizar nenhuma essência, nenhuma vocação histórica ou espiritual, nenhum destino biológico. É a única razão por que algo como uma ética pode existir: pois é evidente que se o homem fosse ou tivesse de ser esta ou aquela substância, este ou aquele destino, não existiria nenhuma experiência ética possível - haveria apenas deveres a realizar." (AGAMBEN, 1993, p. 38, grifo nosso)
} 
emancipatórias $^{48}$. Diz Habermas (1998, p. 296): “assim que deixarmos cair o paradigma da produção podemos afirmar uma relação interna de sentido e validade para todo o reservatório de significado" da sociedade. Ou seja, é na relação interna entre sentido e validade, onde hipoteticamente situamos a informação, que a perspectiva emancipatória é gerada, certamente, de maneira ética: "ética é a maneira que não nos acontece nem nos funda, mas nos gera" (AGAMBEN, 1993, p. 30), em outros termos e complementando, "o ser que se gera nesta linha é o ser qualquer e a maneira como passa do comum ao próprio e do próprio ao comum chama-se uso - ou então ethos." (AGAMBEN, 1993, p. 24)

Reconstruir racionalmente a esfera informacional da sociedade significa admitir que esta ainda não atingiu seu potencial emancipatório, obstacularizado pelas complexas e diversas contrações das esferas públicas de discurso. Agregada ao projeto da modernidade inacabada, a reconstrução racional da dimensão informacional da sociedade aponta para um plano coordenado das ações de informação ("pan-informacionais") com outros plexos acionais da sociedade, cuja farolagem linguístico-discursiva direciona a pluralidade das ações e suas multidiversas formas ao entendimento mútuo. Logo, não se trata de compreender a sociedade como "da informação" - uma regionalização de forte viés econômico -, mas, de perguntar-se acerca das condições de produção, publicização e validação da esfera informacional da existência humana - "de todos", uma universalização inter-ativa (iteração democrática) - para uma vida comum "boa" e "tolerável”. Intuitivamente, a corporificação desta "utopia realista" de uma sociedade da informação que vem, em nossa leitura, passa ao menos por dois eixos interpretativos que se encontram neste momento: o que Giorgio Agamben denominou de experimentum linguae, a experiência ética (humana) da linguagem ${ }^{49}$, cuja expressão justa é "a vida humana enquanto ethos, enquanto vida ética” (AGAMBEN, 2008 , p. 17) e o que a reconstrução racional circunscreve como meta-meios para a

\footnotetext{
48 “[...] a perspectiva da emancipação não resulta de modo nenhum do paradigma da produção, mas sim do paradigma do agir orientado no sentido do entendimento mútuo. É a forma dos processos de interação que tem de ser modificada, se se quiser descobrir no plano prático o que é que os membros de uma sociedade poderiam querer em dada situação, bem como o que é que eles deveriam fazer em prol do seu interesse comum. [...] Quanto ao modo como poderia ser fundamentada esta ideia da razão, entendida como uma ideia implícita factualmente nas relações de comunicação e a ser alcançada no plano prático, acerca disso nada poderá dizer uma teoria que se obstine no paradigma da produção." (HABERMAS, 1998, p. 87-88, grifo nosso)

${ }^{49} \mathrm{O}$ experimentum linguae também está inscrito na Conferência sobre ética de Wittgenstein: "E agora descreverei a experiência de maravilhar-se com a existência do mundo dizendo: é a experiência de ver o mundo como um milagre. Neste momento sou tentado a dizer que a expressão justa na língua para o milagre da existência do mundo, mesmo não sendo nenhuma proposição na língua, é a existência da própria linguagem." (WITTGENSTEIN, 2013, grifo nosso)
} 
emancipação: a linguagem e a dignidade humana; ambos partilham da "tarefa da humanidade que vem" (que aprende) $)^{50}$.

\section{REFERÊNCIAS}

AGAMBEN, Giorgio. A comunidade que vem. Lisboa: Presença, 1993.

AGAMBEN, Giorgio. Estado de exceção. São Paulo: Boitempo, 2004.

AGAMBEN, Giorgio. Infância e história: destruição da experiência e origem da história. Belo Horizonte: Editora UFMG, 2008.

BATES, Benjamin J. Information as an economic good: a re-evaluation of theoretical Approaches. In: RUBEN, B. D.; LIEVROUW, L. A. (Eds.) Mediation, Information, and Communication. New Brunswick: Transaction, 1990. p. 379-394.

BENHABIB, Seyla. Toward a Deliberative Model of Democratic Legitimacy. In: BENHABIB, Seyla (Ed.) Democracy and difference: contesting the boundaries of the political. Princeton: Princeton University Press, 1996. p. 67-94.

BENJAMIN, Walter. Magia e técnica, arte e política: ensaios sobre a literatura e história da cultura. São Paulo: Brasiliense, 1987.

BERGER, Peter L.; LUCKMANN, Thomas. A construção social da realidade: tratado de sociologia do conhecimento. Petrópolis: Vozes, 2009.

BOLTANSKI, Luc; CHIAPELLO, Eve. O novo espírito do capitalismo. São Paulo, SP: Wmfmartinsfontes, 2009.

BOURDIEU, Pierre. Esboço de uma teoria da prática. In: ORTIZ, Renato (Org.). Pierre Bourdieu: sociologia. São Paulo: Ática, 1983. p. 46-81.

BRIER, Søren. The Transdisciplinary View of Information Theory from a Cybersemiotic Perspective. In: IBEKWE-SANJUAN, Fidelia; DOUSA, Thomas M. (Eds.) Theories of Information, Communication and Knowledge: a multidisciplinary approach. Londres: Springer, 2014.

BRIET, Suzanne. What is Documentation? Indiana: Scarecrow Press, 2006.

CAPURRO, Rafael. La libertad en la era digital. Informatio, v. 19, n. 1, p. 5-23, 2014.

CAPURRO, Rafael. Notes on Greek, Latin, Arabic, and Persian Roots of the concept of information. 2014a. Disponível em: < http://www.capurro.de/iran.html>. Acesso em: 20 de março de 2016.

\footnotetext{
${ }^{50}$ Por meio da perspectiva agambeniana, crítico-filológica, há uma tentativa hermenêutica de análise da informação no curso da "tarefa in-fantil da humanidade que vem”, em Menezes (2015).
} 
CAPURRO, Rafael. What is Information Science for? a philosophical reflection. In: VAKKARI, P.; CRONIN, B. (Ed.). Conceptions of Library and Information Science; historical, empirical and theoretical perspectives. In: International Conference for the celebration of 20th anniversary of the Department of Information Studies, University of Tampere, Finland.1991. Proceedings... London, Los Angeles: Taylor Graham, 1992. p. 8296.

CAPURRO, R.; HJORLAND, B. O conceito de informação. Perspectivas em Ciência da Informação, v. 12, n. 1, p. 148-207, jan./ abr. 2007.

CASTELLS, Manuel. Fim de milênio. 2. ed. São Paulo, SP: Paz e Terra, 2000.

CASTELLS, Manuel. O poder da identidade. 3. ed. São Paulo, SP: Paz e Terra, 2001.

CASTELLS, Manuel. A sociedade em rede. 2. ed. São Paulo, SP: Paz e Terra, 1999.

CHARTIER, Roger. Origens culturais da Revolução Francesa. São Paulo: Ed. UNESP, 2009.

DAY, Ronald. The modern invention of information: discourse, history and power. Southern Illinois: Southern Illinois University Press, 2001.

DUFF, Alistair. The Normative Crisis of the Information Society. Cyberpsychology: Journal of Psychosocial Research on Cyberspace, v. 2, n. 1, 2008.

GARFINKEL, Harold. Toward a sociological theory of information. London: Paradigm Publishers, 2008.

GONZÁLEZ DE GÓMEZ, Maria Nélida. O caráter seletivo das ações de informação.

Informare, Rio de Janeiro, v. 5, n.2, p. 7-31, 1999.

GONZÁLEZ DE GÓMEZ, Maria Nélida. Habermas, informação e argumentação. In: O pensamento vivo de Habermas: uma visão interdisciplinar. In: PINZANI, Alessandro, LIMA, Clóvis M. de, DUTRA, Delamar V. (Coord.). Florianópolis: NEFIPO - UFSC, 2009. p. 115-139.

GONZÁLEZ DE GÓMEZ, Maria Nélida. A informação: dos estoques às redes. Ciência da Informação, Brasília, v. 24, n. 1, p. 77-83, 1995.

GONZÁLEZ DE GÓMEZ, Maria Nélida. A informação como instância de integração de conhecimentos, meios e linguagens. Questões epistemológicas, consequências políticas. In: GONZALEZ DE GOMEZ, M.N.; DILL ORICO, E.G. Políticas de memória e informação: reflexos na organização do conhecimento. Natal: EDUFRN, 2006, p. 29-84.

GONZÁLEZ DE GOMEZ, Maria Nélida. A universidade e a "sociedade da informação". Rev. Dig. Bibl. Ci. Inf., v. 9, n. 1, p.225-242, jul./dez. 2011.

HABERMAS, J. Discurso filosófico da modernidade. Lisboa: Dom Quixote, 1998. 
HABERMAS, Jürgen. Entre naturalismo e religião: estudos filosóficos. Rio de Janeiro: Tempo Brasileiro, 2007.

HABERMAS, Jürgen. Fundamentação linguística da sociologia. Lisboa: edições 70, 2010a. (Obras escolhidas, 1)

HABERMAS, Jürgen. "A modernidade: um projeto inacabado?”. In: ARANTES, Otília Beatriz Fiori; EDUARDO, Paulo (Orgs.) Um ponto cego no projeto moderno de Jürgen Habermas: arquitetura e dimensão estética depois das vanguardas. São Paulo: Brasiliense, 1992.

HABERMAS, Jürgen. La reconstrucción del materialismo histórico. Madrid: Taurus, 1992.

HABERMAS, Jürgen. Para a reconstrução do materialismo histórico. São Paulo: Brasiliense, 1983.

HABERMAS, Jürgen. No turbilhão da tecnocracia: um apelo por solidariedade europeia.

Direito.Unb, v. 1, n. 2, p. 11-32, 2014.

HALL, Kent. The economic nature of information. The information society: an international journal, v. 1, n. 2, p. 143-166, 1981.

HEIDEGGER, Martin. Ensaios e conferências. 6. ed. Petrópolis: Vozes, 2010

HEIDEGGER, Martin. Os pensadores. São Paulo: Abril Cultural, 1973.

HONNETH, Axel. El derecho de la libertad: esbozo de una eticidad democrática. Madrid: Katz Editores, 2014.

HONNETH, Axel. Patologías de la razón: historia y actualidad de la teoría crítica. Madrid: Katz Editores, 2009.

HORKHEIMER, Max. Teoria tradicional e teoria crítica. In: BENJAMIN, Walter; HORKHEIMER, Max; ADORNO, Theodor W; HABERMAS, Jürgen. Textos escolhidos. São Paulo, SP: Abril Cultural, 1975. (Os pensadores, XLVIII)

LUHMANN, Niklas. Introducción a la teoría de sistemas. Ciudad de México: Universida Iberoamericana, 2002.

MACHLUP, Fritz. Knowledge: its creation, distribution and economic significance. Princeton: Princeton University Press, 1984.

MANIN, Bernard. On legitimacy and political deliberation. Political theory, v. 15, n. 3, p. 338-368, 1987.

MATTELART, Armand. Historia de la sociedad de la información. Barcelona: Paidós, 2002.

McCARTHY, Thomas. La teoria critica de Jurgen Habermas. Madrid: Ed. Tecnos, 2013. 
MENEZES, Vinícios Souza de. Informação, um excurso crítico-filológico. Perspectivas em Ciência da Informação, v. 20, n. 1, p. 3-18, jan./ mar.,2015.

NOBRE, Marcos; REPA, Luiz (Orgs.). Habermas e a reconstrução: sobre a categoria central da teoria crítica habermasiana. Campinas: Papirus Editora, 2012.

NUNES, Benedito. Passagem para o poético: filosofia e poesia em Heidegger. São Paulo: Ática, 2012.

OLIVEIRA, Nythamar. Breves observações sobre normatividade e naturalismo. In: MÜLLER, Felipe de Matos, RODRIGUES, Tiegue Vieira (Orgs.) Epistemologia social: dimensão social do conhecimento. Porto Alegre: Edipucrs, 2012. p. 145-161.

OLIVEIRA, Manfredo Araújo de. Reviravolta linguístico-pragmática na filosofia contemporânea. São Paulo: Loyola, 1996.

PEDERSEN, Jørgen. Habermas' method: rational reconstruction. Philosophy of the Social Sciences, v. 38, n. 4, p. 457-485, 2008.

PORAT, Marc U. The information economy: definition and measurement. Washington: Office of Telecomunication, 1977.

RAWLS, Anne Warfield. Editor's Introduction. In: GARFINKEL, Harold. Toward a sociological theory of information. London: Paradigm Publishers, 2008.

RENDÓN ROJAS, Miguel Ángel. Bases teóricas y filosóficas de la bibliotecología. Ciudad de México: UNAM, 2005.

REPA, Luiz. Compreensões de reconstrução: sobre a tipologia das formas de reconstrução de Robin Celikates. In: ANAIS DO X COLÓQUIO HABERMAS E I COLÓQUIO DE

FILOSOFIA DA INFORMAÇÃ̃, 2014, Rio de Janeiro. Anais... Rio de Janeiro: Salute, 2014.

ROBERTS, Norman. A search for information man. Social Science Information Studies, v. 2, p. 93-104, 1982.

SENNETT, Richard. A cultura do novo capitalismo. Rio de Janeiro: Record, 2006.

SENNETT, Richard. O declínio do homem público: as tiranias da intimidade. São Paulo: Companhia das Letras, 1988.

SHANNON, Claude E.; WEAVER, Warren. A teoria matemática da comunicação. São Paulo: DIFEL, 1975.

VOIROL, Olivier. Teoria crítica e pesquisa social: da dialética à reconstrução. Novos estudos, v. 93, p. 80-99, 2012.

WIENER, Norbert. Cibernética e sociedade: o uso humano de seres humanos. São Paulo: Cultrix, 1968. 
WITTGENSTEIN, Ludwig. Conferência sobre Ética. Trad. Dall'Agnol, Darlei. In: Ética e Linguagem. $3^{a}$ ed. São Leopoldo: Unisinos, 2005, p. 215-224.

WITTGENSTEIN, Ludwig. Cultura e valor. Lisboa: Edições 70, 2000.

WITTGENSTEIN, Ludwig. Investigações filosóficas. 5. ed. Petrópolis: Vozes, 2008. 